\title{
Magnetohydrodynamics (MHD) Flow and Heat Transfer of a Doubly Stratified Nanofluid Using Cattaneo-Christov Model
}

\author{
Najiyah Safwa Khashi’ie ${ }^{1,2, *}$, Norihan Md Arifin ${ }^{1,3}$, Ezad Hafidz Hafidzuddin ${ }^{4}$, \\ Nadihah Wahi ${ }^{3}$, Mohd Rijal Ilias ${ }^{5}$ \\ ${ }^{1}$ Institute for Mathematical Research, Universiti Putra Malaysia, 43400 UPM Serdang, Selangor, Malaysia \\ ${ }^{2}$ Fakulti Teknologi Kejuruteraan Mekanikal dan Pembuatan, Universiti Teknikal Malaysia Melaka, Hang Tuah Jaya, \\ 76100 Durian Tunggal, Melaka, Malaysia \\ ${ }^{3}$ Department of Mathematics, Faculty of Science, Universiti Putra Malaysia, 43400 UPM Serdang, Selangor, Malaysia \\ ${ }^{4}$ Centre of Foundation Studies for Agricultural Science,Universiti Putra Malaysia, 43400 UPM Serdang, Selangor, Malaysia \\ ${ }^{5}$ Department of Mathematical Sciences, Faculty of Computer and Mathematical Sciences, UiTM Shah Alam,
}

40450 Shah Alam, Selangor, Malaysia

Copyright (C) 2019 by authors, all rights reserved. Authors agree that this article remains permanently open access under the terms of the Creative Commons Attribution License 4.0 International License

\begin{abstract}
The present study utilized Cattaneo-Christov heat flux model for solving nanofluid flow and heat transfer towards a vertical stretching sheet with the presence of magnetic field and double stratification. Thermal and solutal buoyancy forces are also examined to deal with the double stratification effects. Buongiorno's model of nanofluid is used to incorporate the effects of Brownian motion and thermophoresis. The boundary layer with non-Fourier energy equations are reduced into a system of nonlinear ordinary (similarity) differential equations using suitable transformations and then numerically solved using bvp4c solver in MATLAB software. The local Nusselt and Sherwood numbers of few limited cases are tabulated and compared with the earlier published works. It showed that a positive agreement was found with the previous study and thus, validated the present method. Numerical solutions are graphically demonstrated for several parameters namely magnetic, thermal relaxation, stratifications (thermal and solutal), thermophoresis and Brownian motion on the velocity, temperature and nanoparticles volume fraction profiles. An upsurge of the heat transfer rate was observed with the imposition of the thermal relaxation parameter (Cattaneo-Christov model) whereas the accretion of thermal and solutal stratification parameters reduced the temperature and nanoparticles concentration profiles, respectively.
\end{abstract}

Keywords Nanofluid, Stretching Sheet, Cattaneo-Christov Model, Double Stratification

\section{Introduction}

Fluid dynamics due to a stretching sheet plays an essential role in the industrial manufacturing applications for example in the extrusion process. The production of sheeting material forms a continuously moving solid surface with inconsistent surface velocity through an or else quiescent fluid [1]. Crane [2] pioneered and obtained an exact solution for the stretched flow of a quiescent fluid. In the past decades, water (viscous fluid) used as a cooling fluid, but it does not seem that water will be the perfect cooling fluid when inspecting the desirable properties of the final product. Subsequently, many researchers analyzed the study with different physical parameters (i.e. magnetic field, suction/injection, heat generation, thermal radiation) and various types of fluids (non-Newtonian fluids, nanofluids). Nanofluids are a contemporary class of heat transfer fluids that have been subject of developing research in the new era. The nanofluids are invented to boost the base fluid's thermal conductivity [3,4]. Choi et al. [5] managed an experiment on nanotube-in-oil suspensions and found that the thermal conductivity is higher compared to the theoretical calculations. Buongiorno [6] and Tiwari and Das [7] introduced the two well-known nanofluid models. There are seven slip mechanisms in the Buongiorno's model which could produce a relative velocity between the nanoparticles and the base fluid, but, only thermophoresis and Brownian motion were effective to model the nanofluid. Khan and Pop [8] were the earliest applied the Buongiorno's model to study the boundary layer flow of a nanofluid towards a stretching sheet.

Cattaneo [9] introduced Maxwell-Cattaneo (MC) law by adopting a thermal relaxation time term to the traditional 
Fourier energy model. However, Christov [10] added a time derivative of heat flux and reformulated the law into a hyperbolic energy equation. Later, there are a few of investigations were examined to validate the stability and uniqueness of the solutions using the new non-Fourier energy model [11-13]. Many recent literatures on the boundary layer flow due to a stretching sheet also considered the non-Fourier energy equation (see [14-27]). Salahuddin et al. [14] found that the temperature profile for MHD flow of Williamson fluid with variable thickness showed a reduction using the heat flux model as compared to the classical energy model. Hayat et al. [15] studied the stagnation point flow of Jeffrey fluid towards a nonlinear stretching surface and a similar conclusion was made. The fluid temperature declined with the increasing values of thermal relaxation parameter. Malik et al. [16] investigated the MHD Casson fluid flow and identified that the temperature deteriorated using the non-Fourier energy model. The similar studies also conducted for various fluid models such as nanofluids [17-19], second grade fluid [20,21], viscoelastic fluid [22, 23], Eyring Powell [24, 25], Carreau fluid [26] and Oldroyd B-fluid [27]. All these results showed that the nonFourier energy model might lead to the reduction of the fluid temperature profile.

Stratification may occur due to the variation of temperature (thermal stratification), concentration (solutal stratification) or both (double stratification). Effect of double stratification is associated in many engineering applications or processes i.e. solar energy, thermal energy storage systems and heat rejection from environment. It is trusted that the effect of stratification correlates to the energy performance. Hence, a few of fundamental studies were scrutinized for the convective flow with the inclusion of stratification effect. Ibrahim and Makinde [28] considered the natural convection of a thermally and solutally stratified viscous flow with the presence of nanoparticles. Mat Yasin et al. [29] applied Tiwari and Das model to solve the mixed convection flow of a thermally stratified nanofluid in a porous medium. The coupled effects of mixed convection and double stratifications for Maxwell and Jeffrey nanofluid models were examined by Hussain et al. [30] and Abbasi et al. [31], respectively. Besthapu et al. [32] investigated the impact of double stratifications on MHD nanofluid due to an exponentially stretching sheet. Daniel et al. [33, 34] considered the mixed effects of MHD, mixed convection, viscous dissipation and Joule heating on both steady and unsteady doubly stratified nanofluid, correspondingly. Very recent, Kandasamy et al. [35] studied the MHD nanofluid towards a porous plate with dual stratifications. All the findings exhibited that the temperature and concentration profiles were depreciated with the increment of thermal and solutal stratification, accordingly.

In the present work, the MHD boundary layer flow and heat transfer of a doubly stratified nanofluid over a stretching sheet is fundametally studied. The Cattaneo-Christov heat flux model is used to represent the energy equation whereas Buongiorno's model of nanofluid is selected to combine the effect of Brownian motion and thermophoresis. The governing model is first transformed into a coupled set of ordinary (similarity) differential equations using a set of transformations and then numerically solved using bvp4c programme in MATLAB soft- ware. Velocity, temperature, and nanoparticles concentration profiles are illustrated in the graphical form using the selected values of the pertinent parameters while the numerical values of the skin friction coefficient, the Nusselt and Sherwood numbers are presented in the table.

\section{Materials and Methods}

Consider a two-dimensional, steady and incompressible flow of a nanofluid due to a stretching sheet with linear velocity $U_{w}(x)=a x$ aligned the $x$-axis while the flow is confined to $y>0$ as depicted in Figure 1. A uniform magnetic field of strength $B_{0}$ is applied perpendicular to the plate with an assumption that the magnetic Reynolds number is adequately small so that the induced magnetic field can be omitted. Thermal and solutal buoyancy forces are also considered to deal with the double stratification effect [32]. The wall temperature and concentration is given by $T_{w}(x)=T_{0}+A x$ and $C_{w}(x)=C_{0}+E x$, correspondingly where $T_{w}>T_{0}$ and $C_{w}>C_{0}$. The linear stratified ambient temperature and concentration are in the form of $T_{\infty}(x)=T_{0}+B x$ and $C_{\infty}(x)=C_{0}+F x$ such that $T_{0}$ and $C_{0}$ are the beginning ambient temperature and concentration of the nanofluid.

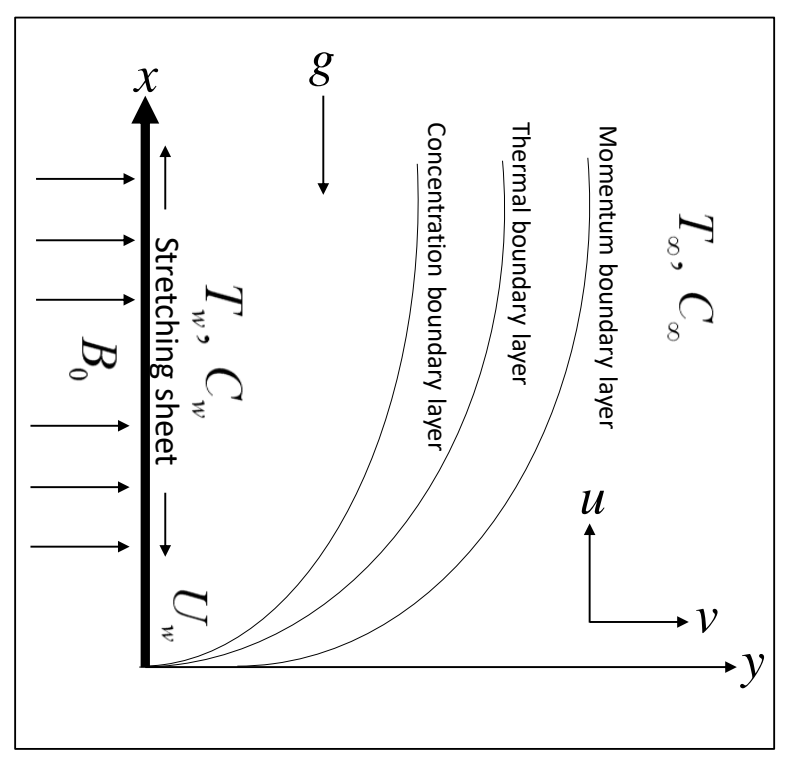

Figure 1. Flow geometry

Under the boundary layer assumptions, the governing model are:

$$
\begin{gathered}
\frac{\partial u}{\partial x}+\frac{\partial v}{\partial y}=0 \\
u \frac{\partial u}{\partial x}+v \frac{\partial u}{\partial y}=\nu \frac{\partial^{2} u}{\partial y^{2}}+\frac{g}{\rho_{f}}\left[\left(1-C_{\infty}\right) \rho_{f_{\infty}} \beta_{T}\left(T-T_{\infty}\right)\right] \\
+\frac{g}{\rho_{f}}\left[\left(\rho_{p}-\rho_{f_{\infty}}\right) \beta_{C}\left(C-C_{\infty}\right)\right]-\frac{\sigma B_{0}^{2}}{\rho_{f}} u
\end{gathered}
$$




$$
\begin{gathered}
u \frac{\partial T}{\partial x}+v \frac{\partial T}{\partial y}+\lambda_{2} T_{\lambda}=\alpha \frac{\partial^{2} T}{\partial y^{2}}+\tau_{1} D_{B} \frac{\partial T}{\partial y} \frac{\partial C}{\partial y} \\
+\tau_{1}\left(\frac{D_{T}}{T_{\infty}}\right)\left(\frac{\partial T}{\partial y}\right)^{2}, \\
u \frac{\partial C}{\partial x}+v \frac{\partial C}{\partial y}=D_{B} \frac{\partial^{2} C}{\partial y^{2}}+\left(\frac{D_{T}}{T_{\infty}}\right) \frac{\partial^{2} T}{\partial y^{2}}
\end{gathered}
$$

in conjunction with the initial and boundary conditions

$$
\begin{gathered}
u(x, 0)=U_{w}(x), \quad v(x, 0)=0, \quad T(x, 0)=T_{w}(x) \\
C(x, 0)=C_{w}(x) \\
u(x, \infty) \rightarrow 0, \quad T(x, \infty) \rightarrow T_{\infty}(x), \quad C(x, \infty) \rightarrow C_{\infty}(x)
\end{gathered}
$$

where

$$
\begin{aligned}
T_{\lambda}=u & \frac{\partial u}{\partial x} \frac{\partial T}{\partial x}+v \frac{\partial v}{\partial y} \frac{\partial T}{\partial y}+u \frac{\partial v}{\partial x} \frac{\partial T}{\partial y}+v \frac{\partial u}{\partial y} \frac{\partial T}{\partial x} \\
+ & 2 u v \frac{\partial^{2} T}{\partial x \partial y}+u^{2} \frac{\partial^{2} T}{\partial x^{2}}+v^{2} \frac{\partial^{2} T}{\partial y^{2}}
\end{aligned}
$$

It is clear that if $\lambda_{2}=0$, the energy equation (3) is reduced to the Fourier energy equation. Further, $(u, v)$ are the velocity components along the $(x, y)$-directions, $T$ and $C$ are the nanofluid temperature and the nanoparticles volume fraction, respectively, $\nu$ is the kinematic viscosity, $\sigma$ is the electrical conductivity of the fluid, $\rho_{f}$ is the density of base fluid, $\rho_{p}$ is the density of nanoparticles, $\lambda_{2}$ is the thermal relaxation time, $k$ is the thermal conductivity of the fluid, $C_{p}$ is the specific heat, $\alpha=\frac{k}{\left(\rho C_{p}\right)_{f}}$ is the thermal diffusivity of the fluid, $\tau_{1}=\frac{\left(\rho C_{p}\right)_{p}}{\left(\rho C_{p}\right)_{f}}$ is the ratio of heat capacity of the nanoparticles to the base fluid, $D_{B}$ and $D_{T}$ are the Brownian and thermophoretic diffusion coefficients, correspondingly.

The governing equations (2)-(4) with the conditions (5) and (6) are simplified by employing the similarity transformations as listed below:

$$
\begin{gathered}
\eta=\sqrt{\frac{U_{w}(x)}{\nu x}} y, \quad \psi=\sqrt{U_{w}(x) \nu x} f(\eta), \\
\theta(\eta)=\frac{T-T_{\infty}(x)}{T_{w}(x)-T_{0}}, \quad \phi(\eta)=\frac{C-C_{\infty}(x)}{C_{w}(x)-C_{0}},
\end{gathered}
$$

where $\eta$ and $\psi$ are the similarity variable and stream function, respectively such that

$$
u=\frac{\partial \psi}{\partial y}=a x f^{\prime}(\eta) \text { and } \quad v=-\frac{\partial \psi}{\partial x}=-\sqrt{a \nu} f(\eta),
$$

which satisfies (1). The resulting nonlinear ordinary differential equations together with the initial and boundary conditions are:

$$
\begin{gathered}
f^{\prime \prime \prime}+f f^{\prime \prime}-\left(f^{\prime}\right)^{2}-M f^{\prime}+\lambda \theta+N \phi=0 \\
\frac{1}{\operatorname{Pr}} \theta^{\prime \prime}+f \theta^{\prime}-f^{\prime} \theta-\delta_{1} f^{\prime}+N b \theta^{\prime} \phi^{\prime}+N t \theta^{2}-\gamma_{T} \theta_{\gamma_{T}}=0 \\
\phi^{\prime \prime}+\operatorname{Pr} L e\left(f \phi^{\prime}-f^{\prime} \phi-\delta_{2} f^{\prime}\right)+\frac{N t}{N b} \theta^{\prime \prime}=0
\end{gathered}
$$

$$
\begin{array}{r}
f(0)=0, \quad f^{\prime}(0)=1, \quad \theta(0)=1-\delta_{1}, \quad \phi(0)=1-\delta_{2} \\
f^{\prime}(\infty) \rightarrow 0, \quad \theta(\infty) \rightarrow 0, \quad \phi(\infty) \rightarrow 0,
\end{array}
$$

where

$$
\theta_{\gamma_{T}}=f^{2} \theta^{\prime \prime}-f f^{\prime} \theta^{\prime}+f^{\prime 2} \theta+f^{\prime 2} \delta_{1}-f f^{\prime \prime} \theta-f f^{\prime \prime} \delta_{1} .
$$

In addition, $f$ is the dimensionless stream function along $x$-direction, $\theta$ is the dimensionless temperature, $\phi$ is the dimensionless nanoparticles volume fraction, $M=\frac{\sigma B_{0}^{2}}{\rho a}$ is the magnetic parameter, $\lambda=\frac{G r}{\operatorname{Re}_{x}^{2}}$ is the thermal buoyancy parameter where $\lambda>0$ and $\lambda<0$ corresponds to the assisting and opposing flow case, accordingly with $G r=$ $\frac{g \rho_{f_{\infty}} \beta_{T}\left(T_{w}-T_{0}\right)\left(1-C_{\infty}\right) x^{3}}{\rho_{f} \nu^{2}}$ and $\operatorname{Re}_{x}=\frac{a x^{2}}{\nu}$. Further, $N=\frac{G c}{\operatorname{Re}_{x}{ }^{2}}$ is the solutal buoyancy parameter, $G c=$ $\frac{g\left(\rho_{p}-\rho_{f_{\infty}}\right) \beta_{C}\left(C_{w}-C_{0}\right) x^{3}}{\rho_{f} \nu^{2}}, \operatorname{Pr}=\frac{\nu}{\alpha}$ is the Prandtl number, $\gamma_{T}=a \lambda_{2}$ is the thermal relaxation parameter, $N b=$ $\frac{\tau_{1} D_{B}\left(C_{w}-C_{0}\right)}{\nu}$ is the Brownian motion parameter, $N t=$ $\frac{\tau_{1} D_{T}\left(T_{w}^{\nu}-T_{0}\right)}{\nu T_{\infty}}$ is the thermophoresis parameter, $L e=\frac{\alpha}{D_{B}}$ is the Lewis number, $\delta_{1}=\frac{B}{A}$ and $\delta_{2}=\frac{F}{E}$ are the thermal and solutal stratification parameters, respectively.

It is noticed that for the case of unstratified nanofluid, the system of ordinary differential equations (10)-(14) is reduced to the model by Akbar et al. [17]. The skin friction coefficient, local Nusselt number (heat transfer rate) and local Sherwood number (mass transfer rate) are defined as (see Akbar et al. [17])

$$
\begin{gathered}
\operatorname{Re}_{x}{ }^{\frac{1}{2}} C_{f}=f^{\prime \prime}(0), \quad \operatorname{Re}_{x}{ }^{-\frac{1}{2}} N u_{x}=-\theta^{\prime}(0), \\
\operatorname{Re}_{x}{ }^{-\frac{1}{2}} S h_{x}=-\phi^{\prime}(0)
\end{gathered}
$$

\section{Results and Discussion}

The nonlinear ordinary (similarity) differential equations in (10)-(12) together with the conditions (13) and (14) are numerically solved using bvp4c solver in MATLAB software. In the bvp4c code, $\eta_{\infty}$ is set up to 15 , however it is found that $\eta=7$ is sufficient enough to achieve the far field boundary conditions for the parameters considered. Velocity, temperature, and nanoparticles concentration profiles are graphically visualized for several values of the control parameters namely magnetic $M$, thermal relaxation $\gamma_{T}$, thermal stratification $\delta_{1}$, solutal stratification $\delta_{2}$, thermophoresis $N t$ and Brownian motion $\mathrm{Nb}$ as shown in Figs. 2-11. For numerical results, $M=\lambda=N=L e=\operatorname{Pr}=1, \delta_{1}=\delta_{2}=0.1$, $\gamma_{T}=0.05$ and $N b=N t=0.2$ have been considered. These values are kept as constant in the study except the varied parameters as shown in figures and tables. Tables 1-3 present the comparison data of $-\theta^{\prime}(0)$ and $-\phi^{\prime}(0)$ for unstratified and 
doubly stratified cases. It shows that all the numerical results in the present work for a limited cases are in favorable agreement with the previously published reports. Therefore, it is believed that this bvp4c programme can efficiently work and the results presented here are correct. Table 4 displays the values of $f^{\prime \prime}(0),-\theta^{\prime}(0)$ and $-\phi^{\prime}(0)$ for several values of $M, \lambda, \gamma_{T}$, $\delta_{1}, \delta_{2}$ and Pr with $N=L e=1$ and $N b=N t=0.2$. The rate of heat transfer increases with the intensification of the thermal relaxation parameter and Prandtl number while decreases with the magnetic, thermal buoyancy and thermal stratification parameters.

Table 1. Comparison data of $-\theta^{\prime}(0)$ for the case of unstratified viscous fluid when $M=\lambda=N=N b=N t=\gamma_{T}=0$ and various values of Pr.

\begin{tabular}{cccc}
\hline $\operatorname{Pr}$ & Present & Khan and Pop [8] & Akbar et al. [17] \\
\hline 0.07 & 0.066056 & 0.0663 & 0.0663 \\
0.2 & 0.169089 & 0.1691 & 0.1691 \\
0.7 & 0.453916 & 0.4539 & 0.4539 \\
2 & 0.911358 & 0.9113 & 0.9114 \\
7 & 1.895403 & 1.8954 & 1.8954 \\
20 & 3.353904 & 3.3539 & 3.3539 \\
70 & 6.462199 & 6.4621 & 6.4622 \\
\hline
\end{tabular}

Velocity profile in Fig.2 depreciates with an increase in $M$ while opposite trend is observed for both temperature and nanoparticles concentration profiles in Figs. 3 and 4 . The magnetic field generally induces a Lorentz force which drag the fluid motion and hence, decelerates the fluid velocity. The opposition between fluid particles also produces heat and as a consequence, both temperature and nanoparticles concentration increase.

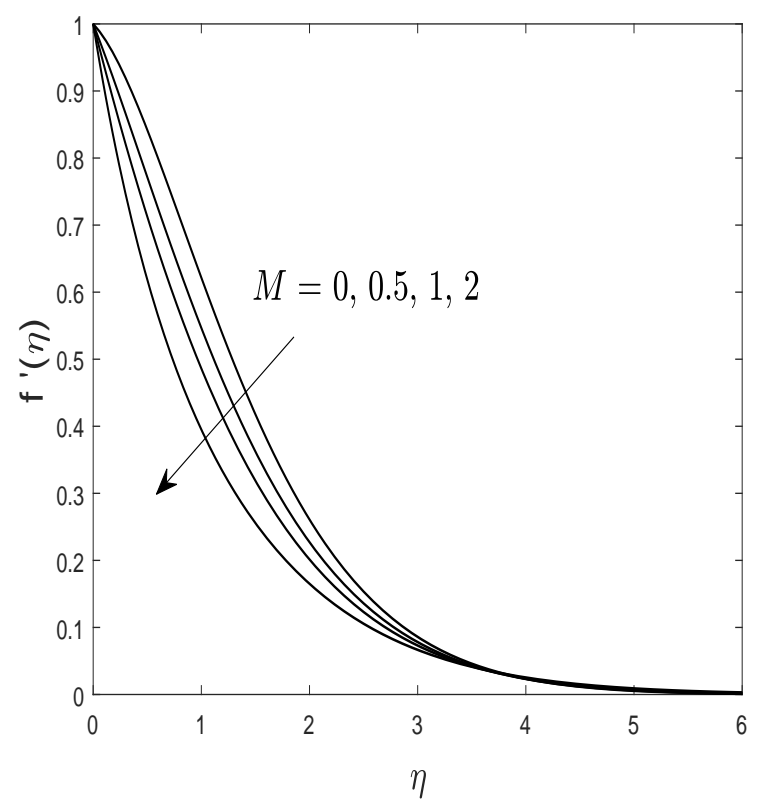

Figure 2. Velocity profile for diverse values of $M$.

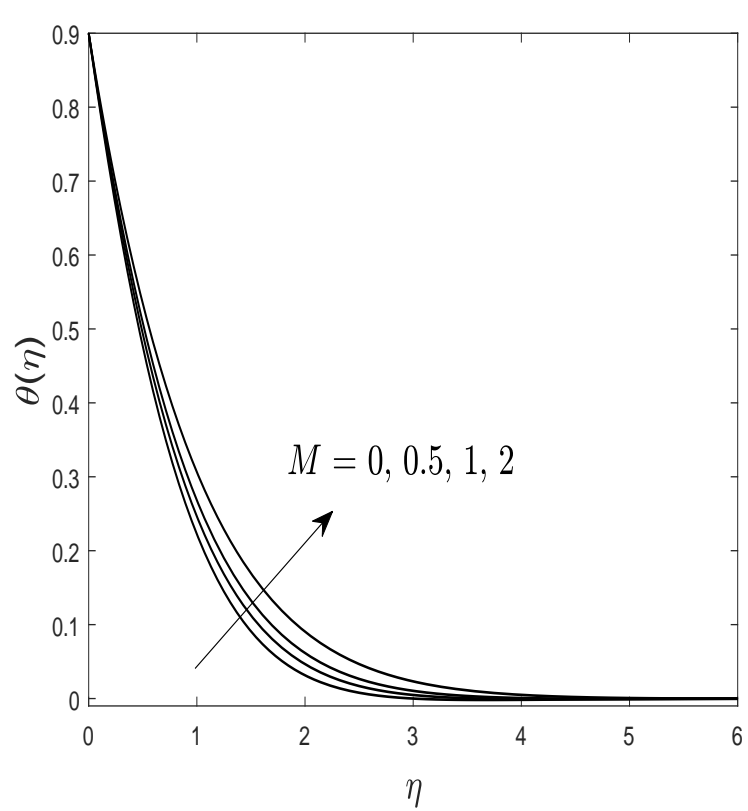

Figure 3. Temperature profile for diverse values of $M$.

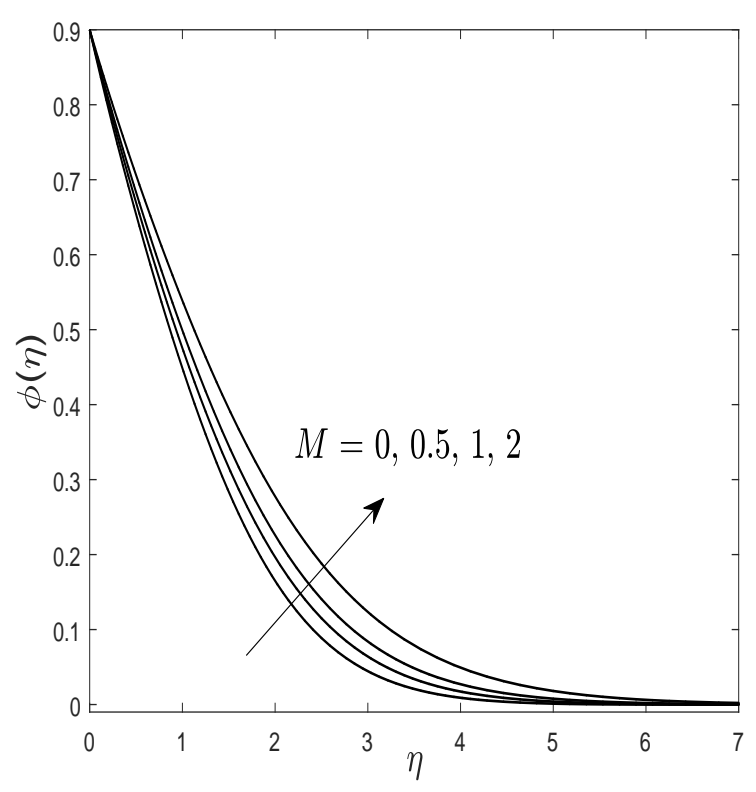

Figure 4. Nanoparticles concentration profile for diverse values of $M$.

Fig. 5 reveals that the nanofluid temperature diminishes with the enhancement of thermal relaxation parameter. The heat transfer process from sheet to the fluid is delayed with the increment of $\gamma_{T}$. It means that the particles of the material require more time to transfer energy to the nearby particles $[14,18]$, hence the temperature is reduced. Figures 6 and 7 exhibit that the temperature and nanoparticles concentration profiles deteriorate as the thermal and solutal stratification parameters increase, respectively. An undershoot of temperature or negative temperature is possible with a higher value of $\delta_{1}$. Hence, it is worth to control the value of $\delta_{1}$ to avoid the nega- 
Table 2. Comparison data of $-\theta^{\prime}(0)$ and $-\phi^{\prime}(0)$ for the case of unstratified nanofluid when $M=\lambda=N=\gamma_{T}=0, \operatorname{Pr}=10, L e=1$ and various values of $\mathrm{Nb}$ and $\mathrm{Nt}$.

\begin{tabular}{ccccccc}
\hline \multirow{2}{*}{$N b=N t$} & \multicolumn{2}{c}{ Present } & \multicolumn{2}{c}{ Khan and Pop [8] } & \multicolumn{2}{c}{ Anwar et al. [36] } \\
& $-\theta^{\prime}(0)$ & $-\phi^{\prime}(0)$ & $-\theta^{\prime}(0)$ & $-\phi^{\prime}(0)$ & $-\theta^{\prime}(0)$ & $-\phi^{\prime}(0)$ \\
\hline 0.1 & 0.952377 & 2.129394 & 0.9524 & 2.1294 & 0.9524 & 2.1294 \\
0.2 & 0.365358 & 2.515223 & 0.3654 & 2.5152 & 0.3654 & 2.5152 \\
0.3 & 0.135514 & 2.608819 & 0.1355 & 2.6088 & 0.1355 & 2.6088 \\
\hline
\end{tabular}

Table 3. Comparison data of $-\theta^{\prime}(0)$ and $-\phi^{\prime}(0)$ for the case of doubly stratified nanofluid when $M=0.49, \lambda=0.3, N=0.09$, $\operatorname{Pr}=L e=1, \gamma_{T}=0$ and $N b=N t=\delta_{1}=\delta_{2}=0.2$.

\begin{tabular}{ccccc}
\hline$\gamma_{T}$ & \multicolumn{2}{c}{ Present } & \multicolumn{2}{c}{ Abbasi et al. [31] } \\
& $-\theta^{\prime}(0)$ & $-\phi^{\prime}(0)$ & $-\theta^{\prime}(0)$ & $-\phi^{\prime}(0)$ \\
\hline 0 & 0.828513 & 0.379802 & 0.82852 & 0.37977 \\
0.05 & 0.855738 & 0.357128 & - & - \\
0.1 & 0.882816 & 0.334568 & - & - \\
\hline
\end{tabular}

Table 4. Numerical values of $f^{\prime \prime}(0),-\theta^{\prime}(0)$ and $-\phi^{\prime}(0)$ for several values of $M, \lambda, \gamma_{T}, \delta_{1}, \delta_{2}$ and $\operatorname{Pr}$.

\begin{tabular}{|c|c|c|c|c|c|c|c|c|}
\hline$M$ & $\lambda$ & $\gamma_{T}$ & $\delta_{1}$ & $\delta_{2}$ & $\operatorname{Pr}$ & $f^{\prime \prime}(0)$ & $-\theta^{\prime}(0)$ & $-\phi^{\prime}(0)$ \\
\hline \multirow[t]{3}{*}{0} & 1 & 0 & 0.1 & 0.1 & 0.7 & -0.08292 & 0.86089 & 0.45037 \\
\hline & & 0.05 & & & & -0.08773 & 0.89192 & 0.42579 \\
\hline & & 0.1 & & & & -0.09230 & 0.92251 & 0.40153 \\
\hline \multirow[t]{20}{*}{1} & & 0 & & & & -0.56674 & 0.79803 & 0.39024 \\
\hline & & 0.05 & & & & -0.56922 & 0.82458 & 0.36870 \\
\hline & & 0.1 & & & & -0.57163 & 0.85089 & 0.34730 \\
\hline & & 0.05 & 0.15 & & & -0.59530 & 0.80642 & 0.36738 \\
\hline & & & 0.2 & & & -0.62140 & 0.78800 & 0.36624 \\
\hline & & & 0.1 & 0.3 & & -0.66603 & 0.81253 & 0.28750 \\
\hline & & & & 0.5 & & -0.76326 & 0.79952 & 0.20586 \\
\hline & 0.5 & & & 0.1 & & -0.73777 & 0.80419 & 0.35444 \\
\hline & -0.5 & & & & & -1.09627 & 0.75407 & 0.31816 \\
\hline & -1 & & & & & -1.29144 & 0.72087 & 0.29314 \\
\hline & 1 & 0 & & & 1 & -0.62745 & 0.93241 & 0.50306 \\
\hline & & 0.05 & & & & -0.63040 & 0.96402 & 0.47791 \\
\hline & & 0.1 & & & & -0.63325 & 0.99535 & 0.45293 \\
\hline & & 0.05 & 0.15 & & & -0.65580 & 0.94458 & 0.47546 \\
\hline & & & 0.2 & & & -0.68123 & 0.92480 & 0.47325 \\
\hline & & & 0.1 & 0.3 & & -0.72325 & 0.95513 & 0.37997 \\
\hline & & & & 0.5 & & -0.81624 & 0.94550 & 0.28097 \\
\hline & 0.5 & & & 0.1 & & -0.78681 & 0.94444 & 0.46175 \\
\hline & -0.5 & & & & & -1.11757 & 0.89749 & 0.42157 \\
\hline & -1 & & & & & -1.29568 & 0.86769 & 0.39493 \\
\hline
\end{tabular}

tive temperature which seems to be physically unacceptable.

Figures 8-11 portray the impact of Brownian motion and thermophoresis parameters on the temperature and nanoparticles concentration profiles. Both parameters arise due to the presence of nanoparticles and nanofluid also known to have a better thermal conductivity as compared to the base fluid (water). The nanofluid temperature upsurges whereas the nanoparticles concentration declines with the augmenting values of Brownian motion parameter. As stated by Akbar et al. [17], 


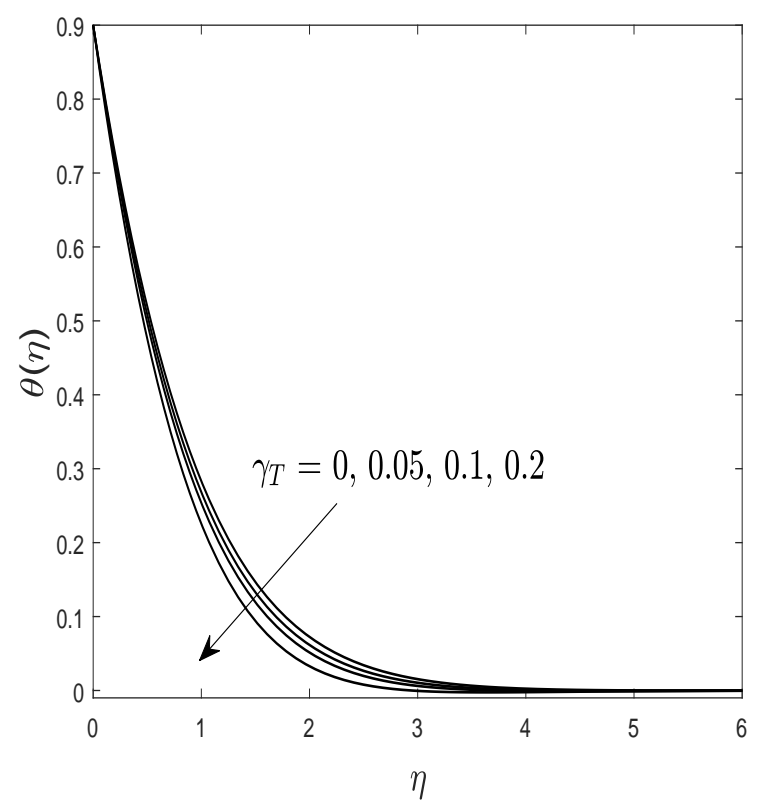

Figure 5. Temperature profile for disparate values of $\gamma_{T}$.

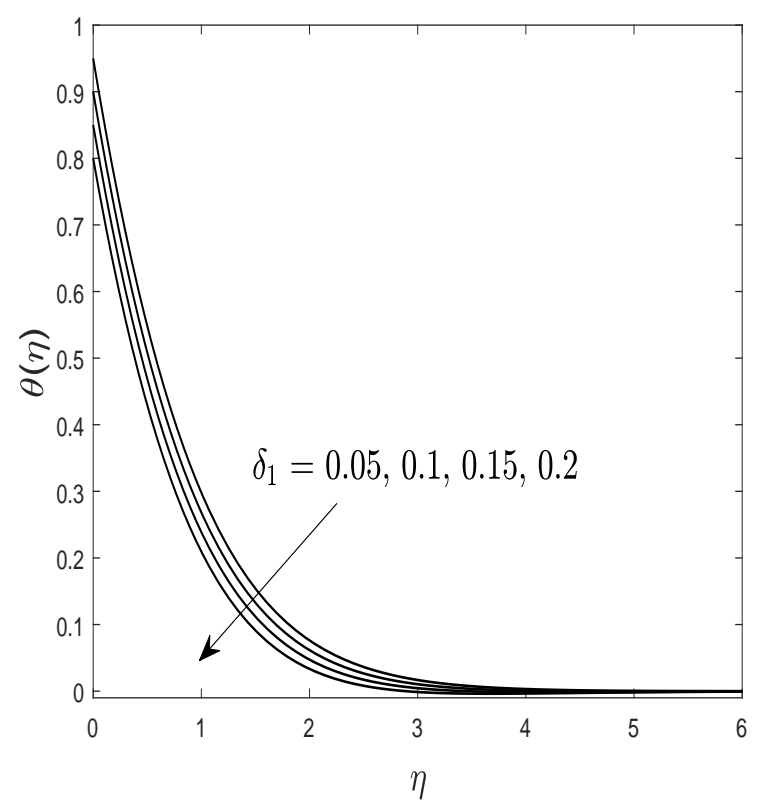

Figure 6. Temperature profile for disparate values of $\delta_{1}$.

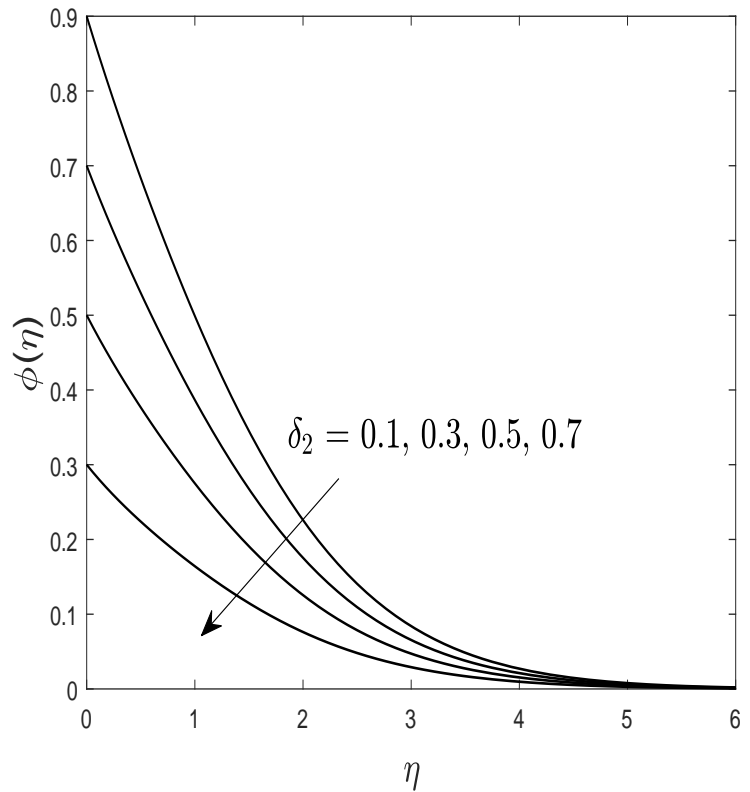

Figure 7. Nanoparticles concentration profile for disparate values of $\delta_{2}$.

higher magnitudes of $N b$ (smaller nanoparticles), could enhance the thermal conduction and this might lead to the enlargement of the temperature.

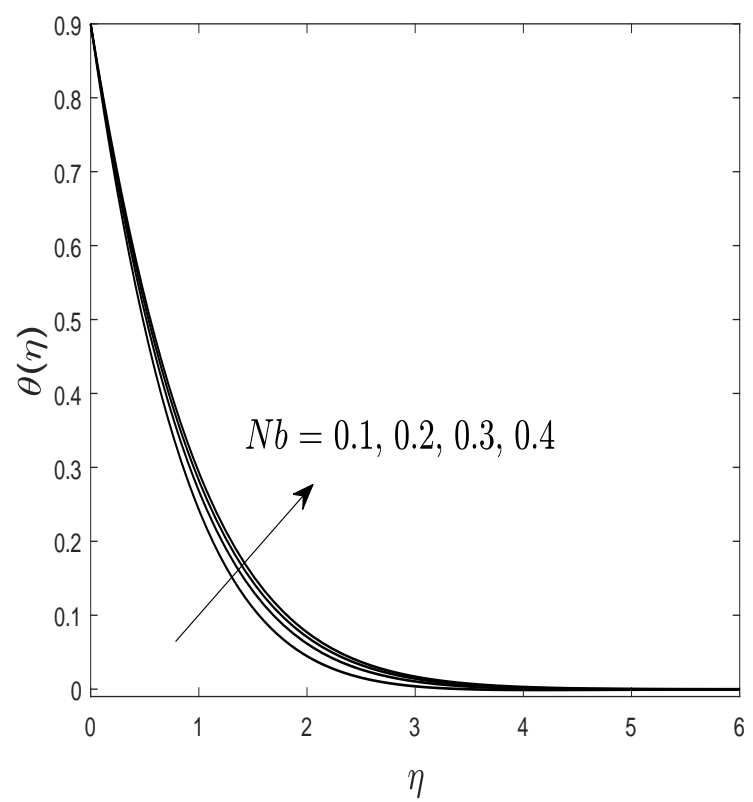

Figure 8. Temperature profile for assorted values of $N b$. 


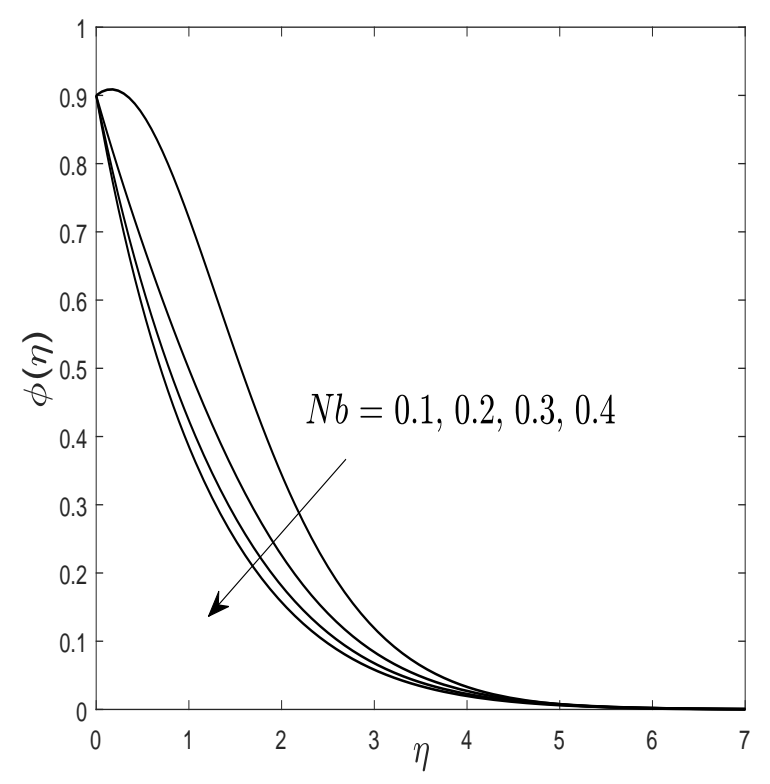

Figure 9. Nanoparticles concentration profile for assorted values of $N b$.

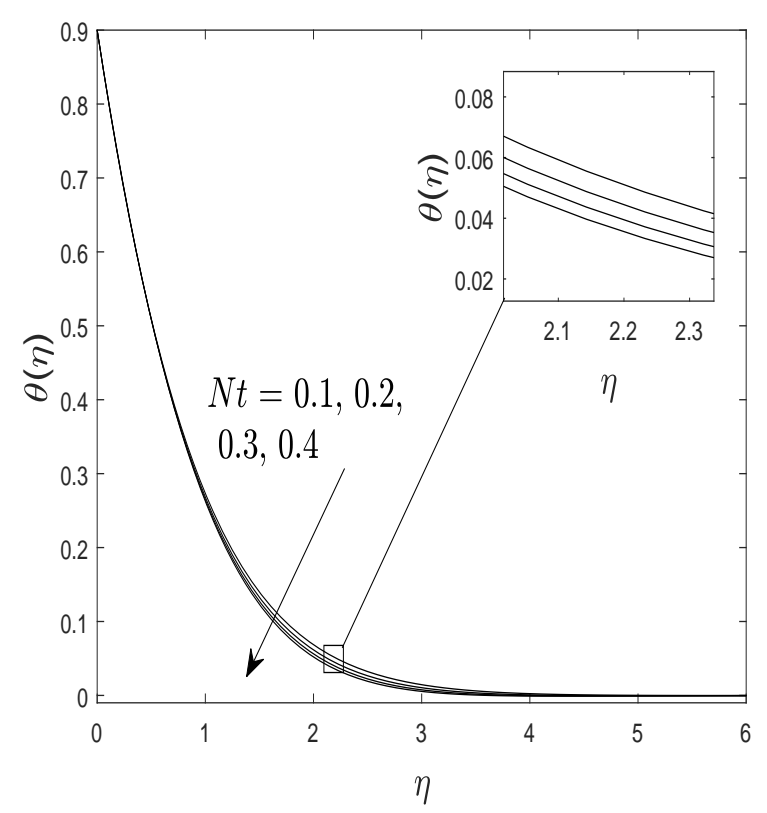

Figure 10. Temperature profile for different values of $N t$.

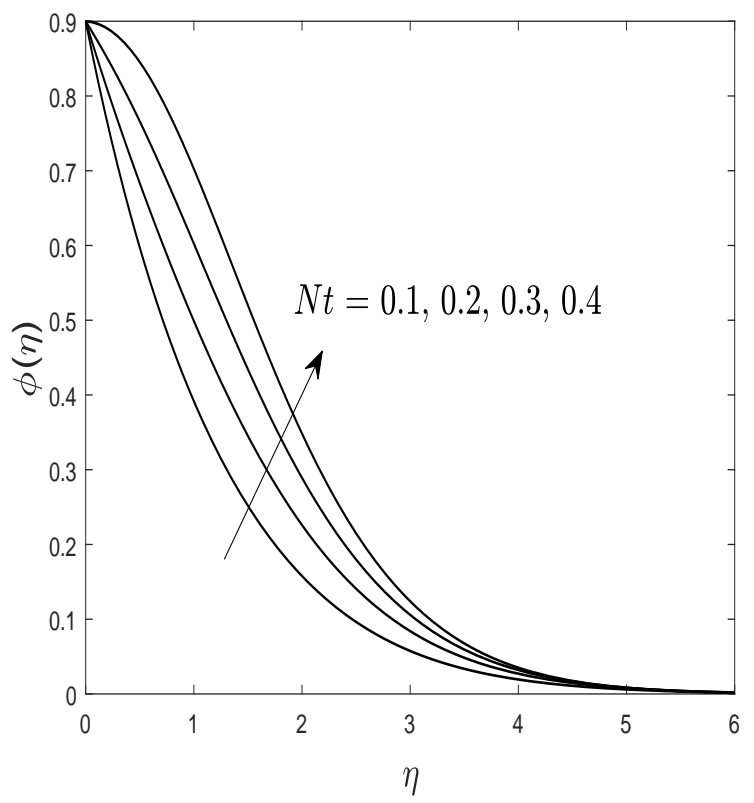

Figure 11. Nanoparticles concentration profile for different values of $N t$.

\section{Conclusions}

In the present work, MHD flow and heat transfer of a doubly stratified nanofluid towards a vertical stretching sheet is analyzed. The classical Fourier energy equation is replaced with the Cattaneo-Christov heat flux model. The Buongiorno's model of nanofluid is chosen to include the effect of Brownian motion and thermophoresis particles deposition. The mathematical model (PDEs) is converted into a system of nonlinear ordinary differential equations (ODEs) using similarity transformations. The bvp4c function in MATLAB software is used to numerically compute the governing boundary value problem. As the conclusions:

- Fluid velocity decreases while the temperature and nanoparticles concentration increase with the enlargement of the magnetic parameter due to the higher of Lorentz force.

- Fluid temperature depreciates with the increment of the thermal relaxation parameter. It shows that the nonFourier heat flux model give a better estimation of the temperature distribution.

- Both temperature and nanoparticles concentration profiles decrease with the accretion of the thermal and solutal stratifications, respectively. It implies that the strength of the thermal and solutal stratifications may affect the displacement of the fluid temperature and concentration.

- Nanoparticles concentration profile declines with the enhancement of Brownian motion parameter while opposite result obtained for the intensity of thermophoresis parameter. 


\section{Acknowledgements}

This research is supported by Universiti Putra Malaysia through the Putra grant-9570600. The authors also appreciate the reviewers who provided insight and expertise that greatly assisted the research. The main author also would like to acknowledge Ministry of Education (Malaysia) and Universiti Teknikal Malaysia Melaka for the financial support through UTEM-SLAB scholarship. We gratefully acknowledge financial support by Universiti Teknologi MARA (UiTM).

\section{REFERENCES}

[1] U.S. Mahabaleshwar, P.V. Kumar, M. Sheremet. Magnetohydrodynamics flow of a nanofluid driven by a stretching/shrinking sheet with suction, SpringerPlus, Vol.5, No.1, 1901, 2016. https://doi.org/10.1186/s40064-016-3588-0.

[2] L.J. Crane. Flow past a stretching plate, Zeitschrift für angewandte Mathematik und Physik ZAMP, Vol.21, No.4, 645-647, 1970. https://doi.org/10.1007/BF01587695.

[3] S.U. Choi, J.A. Estman JA. Enhancing thermal conductivity of fluids with nanoparticles, ASME-Publications-Fed, Vol.231, 99-106, 1995.

[4] F. Mabood, W.A. Khan, A.M. Ismail. MHD boundary layer flow and heat transfer of nanofluids over a nonlinear stretching sheet: a numerical study, Journal of Magnetism and Magnetic Materials, Vol.374, 569-76, 2015. https://doi.org/10.1016/j.jmmm.2014.09.013.

[5] S.U. Choi, Z.G. Zhang, W. Yu, F.E. Lockwood, E.A. Grulke. Anomalous thermal conductivity enhancement in nanotube suspensions, Applied physics letters, Vol.79, No.14, 2252-2254, 2001. https://doi.org/10.1063/1.1408272.

[6] J. Buongiorno. Convective transport in nanofluids, Journal of heat transfer, Vol.128, No.3, 240-250, 2006 doi: $10.1115 / 1.2150834$.

[7] R.K. Tiwari, M.K. Das. Heat transfer augmentation in a two-sided lid-driven differentially heated square cavity utilizing nanofluids, International Journal of Heat and Mass Transfer, Vol.50, No.9-10, 2002-2018, 2007. https://doi.org/10.1016/j.ijheatmasstransfer.2006.09.034.

[8] W.A. Khan, I. Pop. Boundary-layer flow of a nanofluid past a stretching sheet, International journal of heat and mass transfer, Vol.53, No.11-12, 2477-2483, 2010. https://doi.org/10.1016/j.ijheatmasstransfer.2010.01.032.

[9] C. Cattaneo. Sulla conduzione del calore. Atti Sem. Mat. Fis. Univ. Modena, Vol.3, 83-101, 1948.

[10] C.I. Christov. On frame indifferent formulation of the MaxwellCattaneo model of finite-speed heat conduction, Mechanics Research Communications, Vol.36, No.4, 481-486, 2009. https://doi.org/10.1016/j.mechrescom.2008.11.003.

[11] B. Straughan. Thermal convection with the CattaneoChristov model. International Journal of Heat and Mass Transfer, Vol.53, No.1-3, 95-98, 2010. https://doi.org/10.1016/j.ijheatmasstransfer.2009.10.001.
[12] M. Ciarletta, B. Straughan. Uniqueness and structural stability for the Cattaneo-Christov equations, Mechanics Research Communications, Vol.37, No.5, 445-447, 2010. https://doi.org/10.1016/j.mechrescom.2010.06.002.

[13] V. Tibullo, V. Zampoli. A uniqueness result for the CattaneoChristov heat conduction model applied to incompressible fluids, Mechanics Research Communications, Vol.38, No.1, 7779, 2011. https://doi.org/10.1016/j.mechrescom.2010.10.008.

[14] T. Salahuddin, M.Y. Malik, A. Hussain, S. Bilal, M. Awais M. MHD flow of Cattanneo-Christov heat flux model for Williamson fluid over a stretching sheet with variable thickness: Using numerical approach, Journal of magnetism and magnetic materials, Vol.401, 991-997, 2016. https://doi.org/10.1016/j.jmmm.2015.11.022.

[15] T. Hayat, M.I. Khan, M. Farooq, A. Alsaedi, M. Waqas, T. Yasmeen. Impact of Cattaneo-Christov heat flux model in flow of variable thermal conductivity fluid over a variable thicked surface, International Journal of Heat and Mass Transfer, Vol.99, 702-710, 2016. https://doi.org/10.1016/j.ijheatmasstransfer.2016.04.016.

[16] M.Y. Malik, M. Khan, T. Salahuddin, I. Khan. Variable viscosity and MHD flow in Casson fluid with Cattaneo-Christov heat flux model: Using Keller box method. Engineering Science and Technology, an International Journal, Vol.19, No.4, 1985-1992, 2016. https://doi.org/10.1016/j.jestch.2016.06.008.

[17] N.S. Akbar, O.A. Beg, Z.H. Khan. Magneto-nanofluid flow with heat transfer past a stretching surface for the new heat flux model using numerical approach, International Journal of Numerical Methods for Heat \& Fluid Flow, Vol.27, No.6, 12151230, 2017 https://doi.org/10.1108/HFF-03-2016-0125.

[18] R.K. Kumar, S.V. Varma. MHD Boundary Layer Flow of Nanofluid Through a Porous Medium Over a Stretching Sheet with Variable Wall Thickness: Using Cattaneo-Christov Heat Flux Model, Journal of Theoretical and Applied Mechanics, Vol.48, No.2, 72-92, 2018. https://doi.org/10.2478/jtam-20180011.

[19] A. Mahmood, W. Jamshed, A. Aziz. Entropy and heat transfer analysis using Cattaneo-Christov heat flux model for a boundary layer flow of Casson nanofluid, Results in Physics, Vol. 10, 640649, 2018. https://doi.org/10.1016/j.rinp.2018.07.005.

[20] M.I. Khan, Q.Z. Zia, A. Alsaedi, T. Hayat. Thermally stratified flow of second grade fluid with nonFourier heat flux and temperature dependent thermal conductivity, Results in physics, Vol.8, 799-804, 2018. https://doi.org/10.1016/j.rinp.2018.01.015.

[21] T. Hayat, S. Ahmad, M.I. Khan, A. Alsaedi. Investigation of generalized Ficks and Fouriers laws in the second-grade fluid flow, Applied Mathematics and Mechanics-Engl. Ed, 1-4, 2018. https://doi.org/10.1007/s10483-018-2390-6.

[22] J. Li, L. Zheng, L. Liu. MHD viscoelastic flow and heat transfer over a vertical stretching sheet with Cattaneo-Christov heat flux effects, Journal of Molecular Liquids, Vol.221, 19-25, 2016. https://doi.org/10.1016/j.molliq.2016.05.051.

[23] S. Nadeem, S. Ahmad, N. Muhammad. Cattaneo-Christov flux in the flow of a viscoelastic fluid in the presence of Newtonian heating, Journal of Molecular Liquids, Vol.237, 180-184, 2017. https://doi.org/10.1016/j.molliq.2017.04.080. 
[24] T. Hayat, M.I. Khan, M. Waqas, A. Alsaedi. On CattaneoChristov heat flux in the flow of variable thermal conductivity Eyring-Powell fluid, Results in physics, Vol.7, 446-450, 2017. https://doi.org/10.1016/j.rinp.2016.12.034.

[25] T. Hayat, S. Nadeem. Flow of 3D Eyring-Powell fluid by utilizing Cattaneo-Christov heat flux model and chemical processes over an exponentially stretching surface, Results in physics, Vol.8, 397-403, 2018. https://doi.org/10.1016/j.rinp.2017.12.038.

[26] M. Khan. On Cattaneo-Christov heat flux model for Carreau fluid flow over a slendering sheet, Results in physics, Vol.7, 310-319, 2017. https://doi.org/10.1016/j.rinp.2016.12.031.

[27] T. Hayat, M.W. Khan, A. Alsaedi, M. Ayub, M.I. Khan. Stretched flow of Oldroyd-B fluid with Cattaneo-Christov heat flux, Results in Physics, Vol.7, 2470-2476, 2017. https://doi.org/10.1016/j.rinp.2017.06.050.

[28] W. Ibrahim, O.D. Makinde. The effect of double stratification on boundary-layer flow and heat transfer of nanofluid over a vertical plate, Computers \& Fluids, Vol.86, 433-441, 2013. https://doi.org/10.1016/j.compfluid.2013.07.029.

[29] M.H. Mat Yasin, N.M. Arifin, R. Nazar, F. Ismail, I. Pop. Mixed convection boundary layer flow embedded in a thermally stratified porous medium saturated by a nanofluid, Advances in Mechanical Engineering, Vol.5, 121943, 2013. https://doi.org/10.1155/2013/121943.

[30] T. Hussain, S. Hussain, T. Hayat. Impact of double stratification and magnetic field in mixed convective radiative flow of Maxwell nanofluid, Journal of Molecular Liquids, Vol.220, 870878, 2016. https://doi.org/10.1016/j.molliq.2016.05.012.
[31] F.M. Abbasi, S.A. Shehzad, T. Hayat, M.S. Alhuthali. Mixed convection flow of jeffrey nanofluid with thermal radiation and double stratification, Journal of Hydrodynamics, Vol.28, No.5, 840-9, 2016. https://doi.org/10.1016/S1001-6058(16)60686-8.

[32] P.Besthapu, R.U. Haq, S. Bandari, Q.M. Al-Mdallal. Mixed convection flow of thermally stratified MHD nanofluid over an exponentially stretching surface with viscous dissipation effect, Journal of the Taiwan Institute of Chemical Engineers, Vol.71, 307-314, 2017. https://doi.org/10.1016/j.jtice.2016.12.034.

[33] Y.S. Daniel, Z.A. Aziz, Z. Ismail, F. Salah. Effects of thermal radiation, viscous and Joule heating on electrical MHD nanofluid with double stratification, Chinese Journal of Physics, Vol.55, No.3, 630-651, 2017. https://doi.org/10.1016/j.cjph.2017.04.001.

[34] Y.S. Daniel, Z.A. Aziz, Z. Ismail, F. Salah. Double stratification effects on unsteady electrical MHD mixed convection flow of nanofluid with viscous dissipation and Joule heating, Journal of Applied Research and Technology, Vol.15, No.5, 464-476, 2017. https://doi.org/10.1016/j.jart.2017.05.007.

[35] R. Kandasamy, R. Dharmalingam, K.S. Prabhu. Thermal and solutal stratification on MHD nanofluid flow over a porous vertical plate, Alexandria engineering journal, Vol.57, No.1, 121130, 2018. https://doi.org/10.1016/j.aej.2016.02.029.

[36] M.I. Anwar, I. Khan, S. Sharidan, M.Z. Salleh. Conjugate effects of heat and mass transfer of nanofluids over a nonlinear stretching sheet, International Journal of Physical Sciences, Vol.7, No.26, 4081-4092, 2012. https://doi.org/10.5897/IJPS12.358 